\title{
El modelo de expansión de las grandes cadenas minoristas chilenas
}

\author{
Álvaro Calderón Hoffmann
}

$\mathrm{L}$

as empresas chilenas de comercio minorista han logrado construir sólidas ventajas competitivas. Estas se sustentan en un modelo de negocios que aprovecha las sinergias obtenidas de la operación conjunta de una serie de actividades relacionadas. El desarrollo de esta fórmula de comercio minorista integrado surgió directamente de la intensa competencia en un mercado chileno que, por su tamaño limitado, hacía muy difícil ser rentable en un solo segmento de la industria del comercio minorista. La clave del éxito ha sido la combinación de las mejores prácticas de los líderes internacionales con el conocimiento local, una oferta diversificada que incluye servicios bancarios y la capacidad de supervivencia en un mercado altamente competitivo. En este contexto, las compañías de comercio minorista han visto en la expansión internacional la mejor opción para iniciar una trayectoria de crecimiento sustentable. 


\section{Introducción}

Chile fue pionero en reformas económicas (apertura, desregulación y privatización) en América Latina. Luego de un periodo inicial de turbulencia, el país entró en una trayectoria de fuerte crecimiento que lo ha convertido en una de las economías de mejor desempeño de la región. En este renovado entorno, las compañías locales se vieron obligadas a efectuar profundas reestructuraciones. Así, a principios del decenio de 1990, algunas de estas empresas exhibían una alta competitividad en el mercado local. Varios sectores lograron ventajas competitivas importantes, entre ellos, los de telecomunicaciones, generación y distribución de energía eléctrica, algunas ramas de la industria manufacturera, las administradoras de fondos de pensiones (AFP) y el comercio minorista.

En este contexto, algunos mercados chilenos comenzaban a dar señales de saturación. No obstante, de forma paralela, surgían nuevas oportunidades de inversión en otros países de América Latina, como resultado de las reformas que se iniciaban en ellos. Así, pese a que las compañías chilenas no eran tan grandes como algunas de sus competidoras latinoamericanas, su experiencia les permitió emprender ambiciosos planes de internacionalización y superar de este modo las limitaciones de tamaño del mercado interno. Además, este proceso tuvo el estímulo del renovado acceso a financiamiento
— tanto local como extranjero- con el que contaron las mayores empresas del país. De hecho, Chile se convirtió en una suerte de "centro de reciclaje" de fondos internacionales (Calderón y Griffith-Jones, 1995).

En la segunda mitad de la década de 1990, una buena cantidad de empresas chilenas buscó repetir en el exterior los éxitos que habían logrado en el mercado interno. Durante ese período, se invirtieron más de 10.000 millones de dólares, concentrándose esta inversión en América del Sur y especialmente en Argentina, Perú y, en menor medida, en Brasil (gráfico 1). La mayor parte de las primeras inversiones estuvieron vinculadas al sector eléctrico, a través de la compra de activos en los procesos de privatización de los países vecinos. Posteriormente se sumaron otras inversiones en actividades de servicios, resaltando entre ellas las AFP, y en manufacturas. En estas últimas destacaban aquellas actividades vinculadas a recursos naturales, como alimentos y bebidas, celulosa y papel, y manufacturas de metales (cuadro 1). A fines de la década, varias de estas compañías habían logrado una importante presencia regional. No obstante, algunas de las más exitosas —como las compañías eléctricas y las AFP - fueron adquiridas por empresas transnacionales que buscaban establecer una rápida y amplia presencia en América Latina. Asimismo, para muchas la falta de experiencia en el ámbito internacional, el exceso de

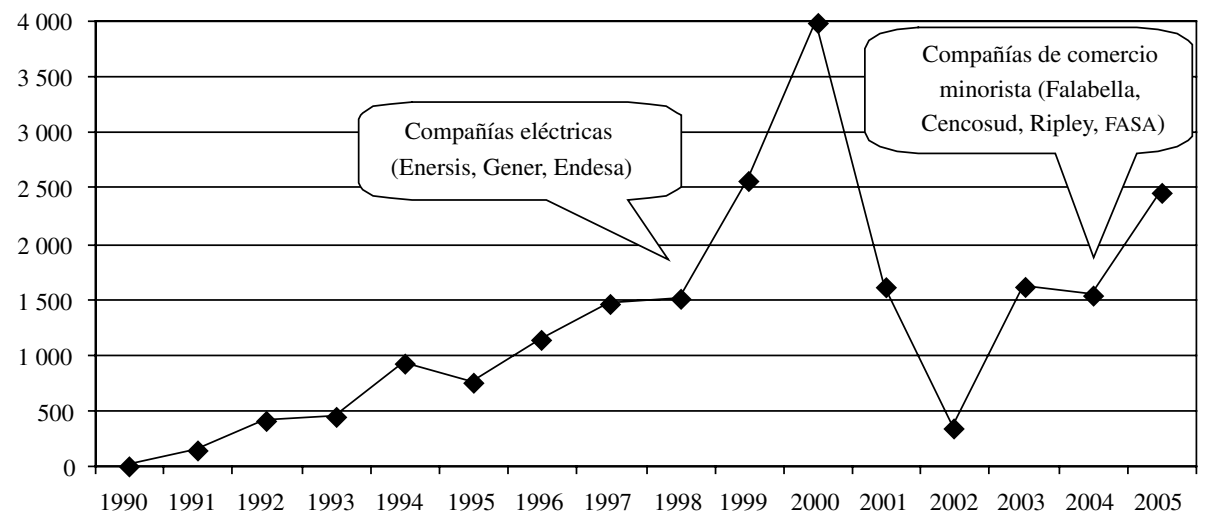

Fuente: Banco Central de Chile. 


\begin{tabular}{|c|c|c|c|c|c|c|c|c|c|c|c|}
\hline \multirow[b]{2}{*}{ A } & \multirow[b]{2}{*}{ B } & \multirow[b]{2}{*}{ Empresa } & \multirow[b]{2}{*}{ Sector } & \multicolumn{6}{|c|}{ Países donde tiene actividades ${ }^{b}$} & \multicolumn{2}{|c|}{ Ventas } \\
\hline & & & & $\mathrm{AR}$ & PE & $\mathrm{BR}$ & MX & OT & $\mathrm{EU}$ & Total & $\begin{array}{l}\% \text { en el } \\
\text { exterior }\end{array}$ \\
\hline 1 & 2 & $\begin{array}{l}\text { Empresa Nacional del Petróleo } \\
\text { (ENAP) }\end{array}$ & Petróleo & $\mathrm{X}$ & $\mathrm{X}$ & & & $\mathrm{X}$ & & 6674 & $\ldots$ \\
\hline 2 & 3 & Enersis $^{c}$ & Energía eléctrica & $\mathrm{X}$ & $\mathrm{X}$ & $\mathrm{X}$ & & $\mathrm{X}$ & & 6277 & $\ldots$ \\
\hline 3 & 4 & Cencosud & Comercio minorista & $\mathrm{X}$ & & & & & & 4915 & 32 \\
\hline 4 & 7 & Falabella & Comercio minorista & $\mathrm{X}$ & $\mathrm{X}$ & & & $\mathrm{X}$ & & 3854 & 22 \\
\hline 5 & 9 & Lan Airlines & Transporte & $\mathrm{X}$ & $\mathrm{X}$ & $\mathrm{X}$ & $\mathrm{X}$ & $\mathrm{X}$ & $\mathrm{X}$ & 2507 & $\ldots$ \\
\hline 6 & 12 & $\begin{array}{l}\text { Celulosa Arauco y Constitución } \\
\text { (ARAUCO) }\end{array}$ & Madera, celulosa y papel & $\mathrm{X}$ & & $\mathrm{X}$ & & $\mathrm{X}$ & & 2377 & $\ldots$ \\
\hline 7 & 13 & $\begin{array}{l}\text { Compañía Manufacturera } \\
\text { de Papeles y Cartones (CMPC) }\end{array}$ & Madera, celulosa y papel & $\mathrm{X}$ & $\mathrm{X}$ & & $\mathrm{X}$ & $\mathrm{X}$ & & 2130 & 11 \\
\hline 8 & 14 & Molymet & Manufacturas de metales & & & & $\mathrm{X}$ & $\mathrm{X}$ & & 2090 & $\ldots$ \\
\hline 9 & 16 & $\begin{array}{l}\text { Compañía General } \\
\text { de Electricidad (CGE) }\end{array}$ & Energía eléctrica & $\mathrm{X}$ & & & & & & 1663 & 10 \\
\hline 10 & 18 & ENTEL & Telecomunicaciones & & $\mathrm{X}$ & & & $\mathrm{X}$ & $\mathrm{X}$ & 1496 & 16 \\
\hline 11 & 19 & Ripley Corp. & Comercio minorista & & $X$ & & & & & 1475 & 25 \\
\hline 12 & 20 & Farmacias Ahumadas (FASA) & Comercio minorista & & $\mathrm{X}$ & $\mathrm{X}$ & $\mathrm{X}$ & & & 1230 & 60 \\
\hline 13 & 23 & $\begin{array}{l}\text { Compañía Cervecerías Unidas } \\
\text { (CCU) }\end{array}$ & Bebidas & $\mathrm{X}$ & & & & & & 961 & 10 \\
\hline 14 & 24 & Embotelladora Andina & Bebidas & $\mathrm{X}$ & & $\mathrm{X}$ & & & & 934 & 52 \\
\hline 15 & 25 & AES Gener ${ }^{\mathrm{c}}$ & Energía eléctrica & $\mathrm{X}$ & $\mathrm{X}$ & & & $\mathrm{X}$ & & 899 & $\ldots$ \\
\hline 16 & 30 & Masisa $^{\mathrm{c}}$ & Madera, celulosa y papel & $\mathrm{X}$ & & $\mathrm{X}$ & $\mathrm{X}$ & & & 744 & 73 \\
\hline 17 & 32 & Manufacturas de Cobre (Madeco) & Manufacturas de metales & $\mathrm{X}$ & $\mathrm{X}$ & $\mathrm{X}$ & & & & 713 & 39 \\
\hline
\end{tabular}

Fuente: elaboración propia con datos de las compañías y de Capital (2006), y América economía (2006a).

a La columna A indica la posición de las empresas si se las ordena por sus inversiones en el exterior, y la columna B indica la posición de las empresas si se las ordena por sus ventas.

b AR: Argentina; PE: Perú; BR: Brasil; MX: México; OT: Otros de América Latina; EU: Estados Unidos.

c Compañía adquirida por una empresa transnacional.

confianza y las difíciles condiciones que enfrentaron en las economías receptoras les significaron grandes pérdidas, de una magnitud similar a las inversiones realizadas.

De este modo, las firmas que decidieron invertir en el exterior tuvieron una experiencia compleja y poco gratificante: fueron adquiridas por competidores extrarregionales o acumularon cuantiosas pérdidas. Así, a pesar del dinamismo de la economía chilena y el acceso a recursos financieros a costos atractivos, los empresarios locales comenzaron a enfrentar con mayor escepticismo y resistencia nuevas iniciativas de expansión fuera del país. Por otro lado, la percepción empresarial del entorno latinoamericano se deterioró rápidamente frente a una mayor volatilidad económica y política en los países vecinos, así como a una menor certeza jurídica respecto a sus intereses en el exterior (Calderón, 2005).

En un ambiente de mayor incertidumbre, las firmas chilenas buscaron afianzar su posición en el mercado local y postergaron gran parte de sus inversiones en el exterior. En Argentina y Perú, particularmente en el primero, las empresas pusieron en marcha planes de contingencia y en algunos casos emprendieron profundos procesos de reestructuración financiera y operativa. Asimismo, las compañías buscaron mejorar su eficiencia en el ámbito local, incorporando nuevas tecnologías y formas de gestión y procurando generar renovadas sinergias. Con este 
fin hubo un fuerte proceso de consolidación a través de fusiones y adquisiciones y de alianzas entre agentes de negocios relacionados, lográndose economías de escala y llevando a cabo intensos procesos de integración. En la actualidad, las empresas chilenas, al parecer, serían más selectivas y cuidadosas al momento de emprender una estrategia de internacionalización.

A partir de 2003, se comenzó a verificar un nuevo repunte de las inversiones chilenas en el exterior; este coincidió con el repunte de la economía interna - cuyas tasas de crecimiento superaron el 6\% en 2004 y 2005- y una gran cantidad de recursos financieros resultantes del dinamismo de la economía internacional y de los buenos precios de los principales productos de exportación del país (gráfico 1). De este modo, ciertos sectores comenzaron a buscar nuevas oportunidades de negocios para seguir creciendo, y ante el tamaño limitado de la economía interna, nuevamente adquirió relevancia la posibilidad de invertir en el exterior. En este escenario, los patrones de la internacionalización no han cambiado de manera significativa, concentrándose en las mismas actividades y destinos geográficos. La recuperación económica y la regularización institucional de Argentina han contribuido de manera importante a consolidar esta tendencia.

Así como en el primer ciclo el sector eléctrico fue el protagonista, en esta nueva fase de las inversiones chilenas en el exterior destacan claramente las compañías de comercio minorista (retail). Estas firmas han aprendido de la experiencia reciente: han desarrollado un modelo de negocios depurado, con claras ventajas competitivas, y han logrado exportarlo con éxito a otros países de América Latina. Las empresas locales aprendieron de los gigantes de la industria a nivel global y adaptaron su experiencia a la realidad latinoamericana, basando sus ventajas competitivas en la capacidad de gestión. De hecho, estas compañías, manteniendo una participación mayoritaria en sus filiales en el exterior, han procurado operar como empresas locales en colaboración con socios estratégicos internos, acotando así el riesgo para el capital que se exporta desde Chile. Esto marca una diferencia con la primera etapa de inversiones chilenas fuera de las fronteras del país, en la cual no existía esta lógica, porque los mercados aún no estaban suficientemente desarrollados.

En síntesis, el proceso de internacionalización de las empresas chilenas se ha dado en el ámbito latinoamericano. Las reformas tempranas, la privatización de empresas estatales y la experiencia acumulada en una economía abierta y competitiva, junto a la proximidad geográfica y cultural, proporcionaron a estas empresas una ventaja competitiva importante al momento de iniciar la expansión internacional de sus actividades y aprovechar las oportunidades que surgían en los países vecinos. En una primera fase, en un entorno de alta incertidumbre, esta experiencia fue fundamental para competir con empresas transnacionales que no conocían bien América Latina. Sin embargo, estas ventajas se degradaron rápidamente, los competidores aprendieron y algunas de las empresas chilenas más activas en este proceso fueron absorbidas por operadores internacionales. En la actualidad, luego de un período de estancamiento, las inversiones chilenas en el exterior están mostrando un nuevo repunte. Las empresas chilenas han aprendido de la experiencia anterior y han desarrollado modelos de negocios que han podido aplicar con éxito en el exterior, siendo el caso más emblemático el del comercio minorista.

\section{II}

\section{La internacionalización del comercio minorista}

A mediados del siglo XIX, en Estados Unidos y Europa se estableció una separación más nítida entre el comercio mayorista y el comercio minorista o al detalle. En Francia se instauraron los grandes almacenes, antecesores de las actuales tiendas por departamentos y origen del comercio minorista, como lo conocemos en la actualidad. Desde sus inicios, los grandes almacenes de París, como las Galerías Lafayette, tuvieron secciones especiales para exhibir sus productos, vendedores orientados a satisfacer las necesidades de los clientes y mecanismos para otorgar crédito. Este modelo se expandió con rapidez a otros países de Europa. Durante la primera mitad del siglo XX, aparecieron en Estados Unidos los supermercados y uno de sus elementos emblemáticos, el "carrito de compras", generando toda una revolución en los patrones de consumo. A principios del decenio de 1960 se introdujeron nuevos formatos que le dieron un renovado impulso a la industria del comercio minorista; la cadena 
francesa Carrefour inauguró el primer hipermercado y en Estados Unidos comenzaron a extenderse los centros comerciales. En estos últimos, convivían tiendas por departamentos, boutiques, supermercados y lugares de entretenimiento (restaurantes, cines y otros). En este contexto comenzaron a consolidarse fuertes operadores locales en los diferentes formatos del comercio minorista, experiencias que se imitaron en todo el mundo.

En América Latina la trayectoria fue similar. A principios del siglo XX comenzaron a aparecer las grandes tiendas en las principales ciudades de la región. Posteriormente, siguiendo el modelo estadounidense, surgieron los primeros supermercados y, poco más tarde, los hipermercados y los centros comerciales. En general, el sector de comercio al detalle creció de manera bastante atomizada y en manos de grupos familiares locales.

A diferencia de lo ocurrido en otras industrias, la internacionalización de las compañías de comercio minorista fue más lenta. Las primeras experiencias en este sentido fueron algunos de los grandes almacenes estadounidenses, como Woolworth en Canadá (1907) y luego en Europa, y Sears Roebuck en Cuba en 1942. En la década de 1960 estas iniciativas fueron emuladas por algunos de sus pares al otro lado del Atlántico, como la francesa C\&A y la británica Marks \& Spencer. Hasta esa fecha, la mayoría de las compañías había centrado su estrategia de crecimiento y diversificación en sus mercados locales. No obstante, estos últimos comenzaban a dar muestras de saturación, lo que, unido a cambios regulatorios y mayor apertura hacia la inversión extranjera directa, estimuló a algunas grandes empresas del rubro a buscar nuevas oportunidades de crecimiento fuera de sus fronteras. En el formato de los supermercados, las compañías europeas fueron las pioneras, y entre ellas destacaron la francesa Carrefour y la holandesa Royal Ahold.

En el decenio de 1990, el proceso comenzó a adquirir mayor dinamismo, particularmente con la irrupción de la estadounidense Wal-Mart. En el año 1990, a menos de treinta años de su fundación, y a través de una activa estrategia de adquisiciones y de consolidación de su formato (tiendas de descuento o conveniencia), dicha compañía se convirtió en la principal cadena de comercio minorista de Estados Unidos. A partir de ese momento, comenzó un ambicioso proceso de expansión internacional, combinando inversiones totalmente nuevas (greenfield investment), compras y asociaciones. En una primera fase se concentró en América del Norte (México en 1991, a través de una asociación con el grupo local Cifra, y Canadá en 1994); luego apuntó hacia América del Sur (Argentina y Brasil en 1995), para finalmente abordar mercados más lejanos en Europa (Alemania en 1998 y Reino Unido en 1999) y Asia (China en 1996, Corea del Sur en 1998 y Japón en 2002). De este modo, Wal-Mart se convirtió en la mayor compañía del rubro en el ámbito global, triplicando las ventas de su más próximo competidor (Carrefour) y escalando hacia las primeras posiciones en la clasificación de las mayores empresas del mundo - Global 500 - que prepara la revista Fortune.

Como lo demuestra la experiencia de Wal-Mart, en la segunda mitad de la década de 1990 la expansión internacional de las empresas de comercio minorista se aceleró notablemente, aunque estuvo concentrada en unos pocos actores relevantes. Además, este proceso no sólo se restringió a países industrializados (Estados Unidos, Europa occidental y Japón) —particularmente como resultado de la conformación de la Unión Europea y del Tratado de Libre Comercio de América del Norte- sino que también se extendió hacia un buen número de economías en desarrollo, principalmente en Asia, América Latina, Europa oriental y la zona del Mediterráneo (gráfico 2 y cuadro 2). Con los mercados de origen al borde de la saturación, varias compañías vieron en las economías emergentes, donde el modelo de negocio estaba poco desarrollado, una gran posibilidad para seguir creciendo. ${ }^{1}$

Con todo, las compañías de comercio minorista de Estados Unidos son las dominantes, siendo responsables del $36 \%$ de las ventas de las 250 mayores empresas de la industria, seguidas por las europeas (35\%) y las de Japón (16\%) (Deloitte, 2006). Como resultado de la expansión internacional, las operaciones externas de estas compañías comenzaron a tener un impacto importante en sus ventas totales. Entre 1996 y 2003, el número de compañías de comercio minorista entre las mayores 100 empresas transnacionales del mundo pasó de ninguna a cuatro: Carrefour, Wal-Mart, Royal Ahold y la alemana Metro (UNCTAD, 1998, pp. 36-38, y 2005, pp. 267-269). Sin embargo, los retornos desde el exterior comenzaron a rezagar el desempeño interno, y ninguna de estas compañías ha surgido como un ganador claro a través de todas las regiones o mercados (McKinsey Global Institute, 2003).

\footnotetext{
${ }^{1}$ A comienzos de la presente década, Royal Ahold poseía una cadena de tiendas con operaciones en Europa occidental y oriental, América del Norte, Centroamérica y América del Sur, y el Sudeste de Asia; Carrefour mantenía una fuerte presencia en Europa, América, Asia, además de Medio Oriente y África; y Wal-Mart actuaba en América, Europa occidental y Asia oriental.
} 
GRÁFICO 2

Mercados de países en desarrollo con mayor potencial para el comercio minorista, por región, 1995-2006

$(\text { En porcentaje })^{\mathrm{a}}$

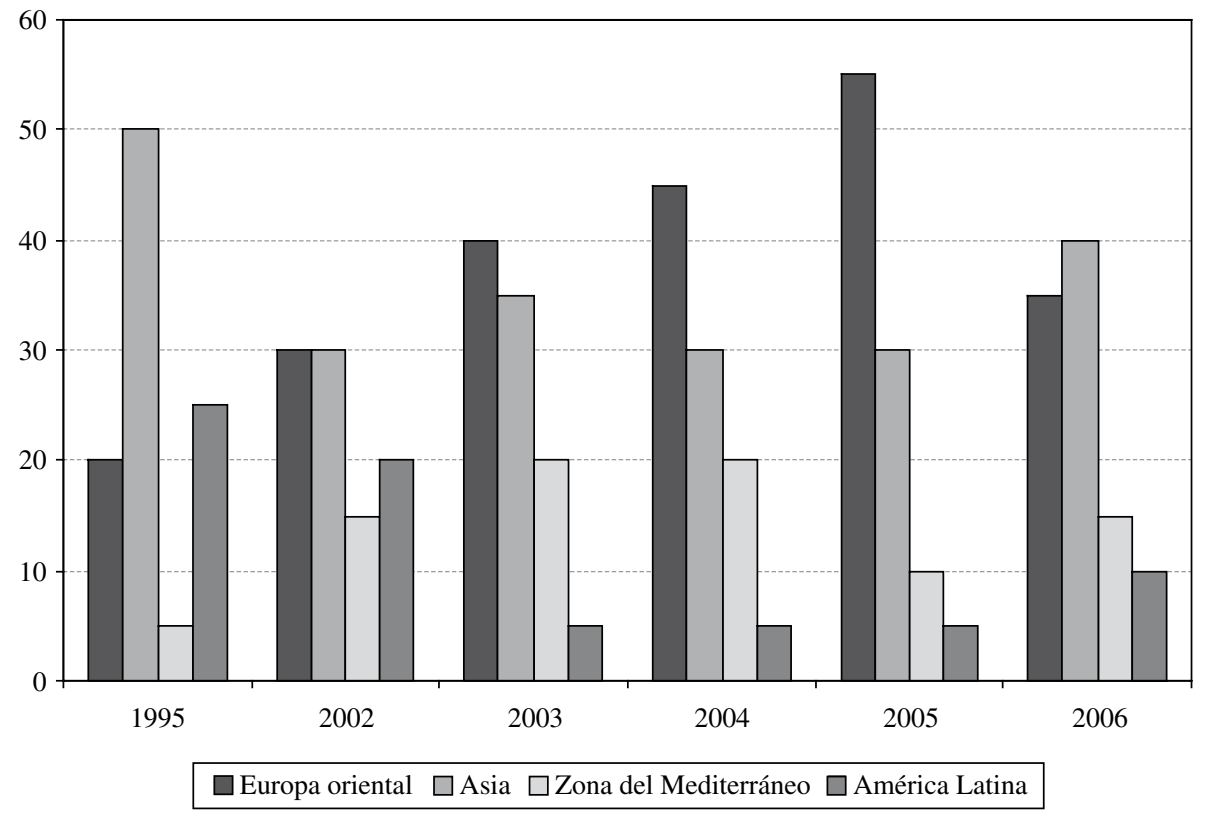

Fuente: elaboración propia sobre la base de A.T. Kearney (varios años).

a Porcentaje de mercados que están entre los 20 destinos más atractivos para el desarrollo de negocios de comercio minorista.

CUADRO 2

Mayores compañías de comercio minorista del mundo, por ventas, 2004

(En millones de dólares)

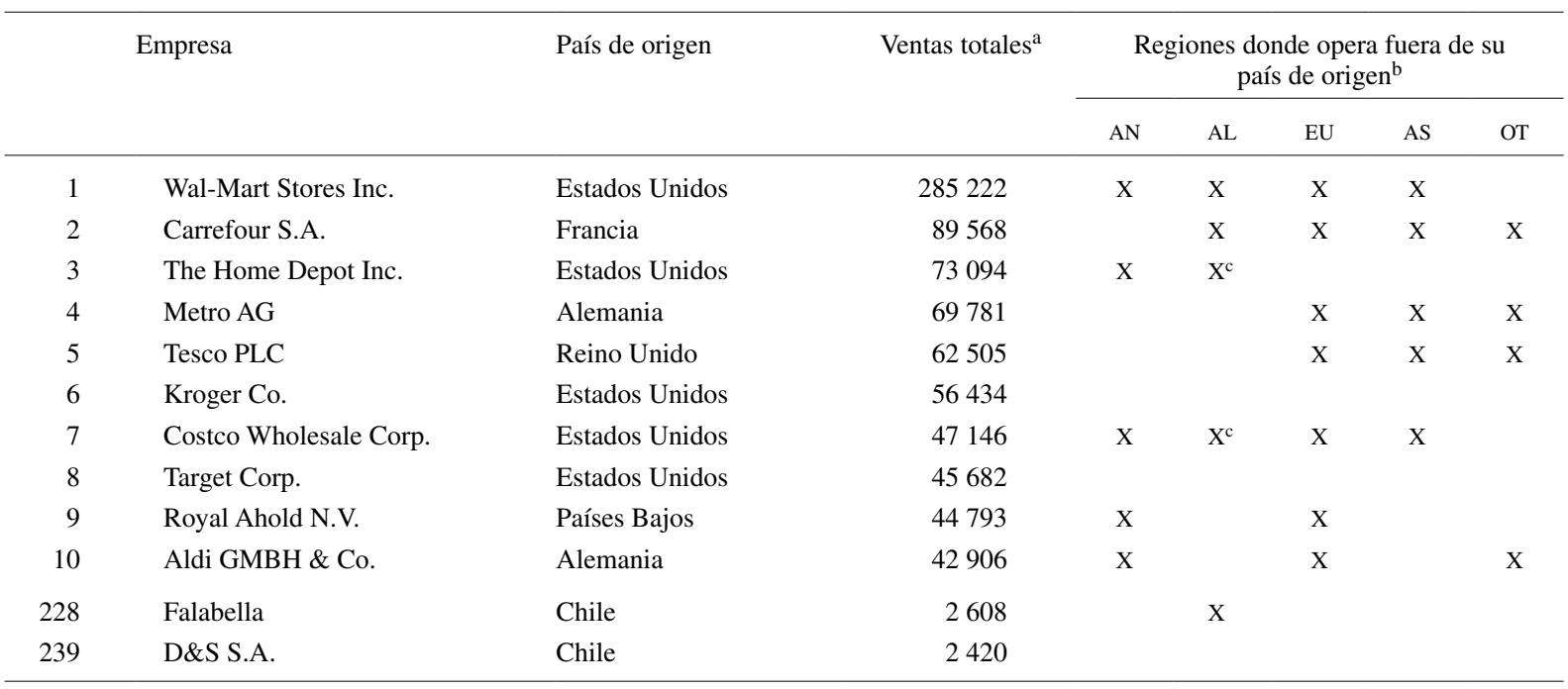

Fuente: elaboración propia sobre la base de Stores (2006).

a Incluyen las ventas del grupo en el segmento de comercio minorista.

b AN: América del Norte (Estados Unidos y Canadá); AL: América Latina y el Caribe; EU: Europa occidental y oriental; AS; Asia; OT: Otros.

c Con operaciones solo en México. 
En este contexto, la reformas y las promisorias perspectivas económicas de los principales países latinoamericanos transformaron a la región en una de las de mayor potencial para la expansión internacional de las principales compañías de la industria con ambiciones globales $^{2}$ (gráfico 2). Así, América Latina se convirtió rápidamente en uno de los objetivos prioritarios para los grandes operadores de comercio minorista (gráfico 3). A través de una agresiva estrategia, que consistió básicamente en adquirir cadenas locales, Wal-Mart, Carrefour y Royal Ahold lograron rápidamente una sólida posición en los mayores mercados regionales (Argentina, Brasil y México) y se convirtieron en algunas de las principales empresas transnacionales con operaciones en la región y líderes de la industria latinoamericana de comercio minorista.

A pesar de las barreras de entrada, estos grandes mercados permitían que las empresas descritas lograsen las economías de escala suficientes para introducir de manera gradual los formatos desarrollados en sus países de origen. En Brasil, el comercio minorista estaba muy atomizado, presentaba bajos márgenes operacionales y elevada necesidad de inversión, y, además, enfrentaba una intensa competencia del sector informal, por lo que se dio un gran valor al ingreso de capital extranjero a la industria. Esto condujo a un alto nivel de penetración de los operadores internacionales, en especial las compañías francesas Carrefour y Casino, la portuguesa Sonae, la holandesa Royal Ahold y, más recientemente, Wal-Mart. Por otro lado, en México, donde existían operadores locales mejor posicionados, Wal-Mart ingresó al mercado mediante una asociación que le permitió conocer las preferencias y necesidades de los consumidores internos. Posteriormente, la firma estadounidense tomó el control de la operación ${ }^{3}$ y aplicó una agresiva estrategia de precios y de transferencia de las mejores prácticas, lo que se tradujo en un incremento significativo de la competencia en el mercado mexicano. Esta experiencia le permitió a Wal-Mart profundizar y acelerar su expansión en América Latina, particularmente en Brasil, donde adquirió los activos de Royal Ahold y de

GRÁFICO 3

América Latina: mercados más atractivos para la industria del comercio minorista (Posición del país entre los 30 mercados emergentes más atractivos) ${ }^{a}$

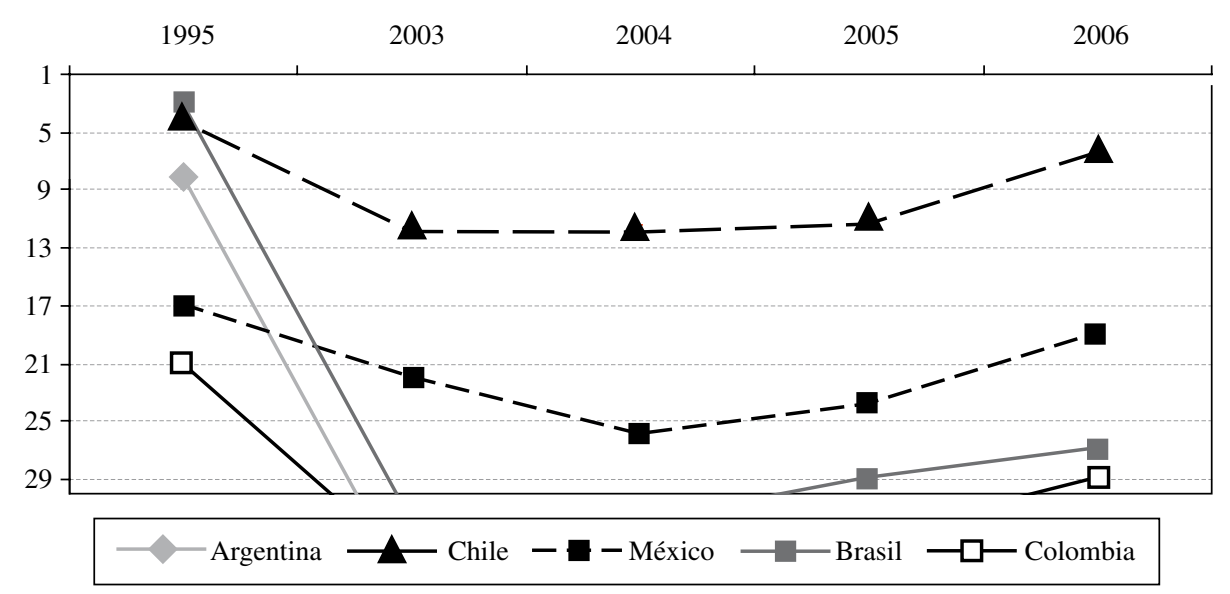

Fuente: elaboración propia con información de A.T. Kearney (varios años).

a A.T. Kearney publica un índice sobre las perspectivas globales del comercio minorista en países en desarrollo. Este análisis pretende ayudar a los operadores internacionales a priorizar sus estrategias globales. El índice se construye sobre la base de variables asociadas al riesgo-país, el grado de atracción y saturación del mercado y el tiempo necesario para aprovechar la oportunidad. Así, se construye una clasificación anual que ordena los 30 principales países emergentes según su potencial de atracción.

\footnotetext{
${ }^{2}$ En 1995, cinco países latinoamericanos figuraban entre los 20 destinos más atractivos para el desarrollo de la industria del comercio minorista. En ese mismo momento, Asia tenía en esa lista diez países, Europa oriental cuatro y la zona del Mediterráneo solo uno (A.T. Kearney, 2005).
}

\footnotetext{
${ }^{3}$ En 1997, Wal-Mart adquirió la participación del Grupo Cifra en la operación conjunta que ambos poseían en México, por la que pagó 1.200 millones de dólares.
} 
Sonae. ${ }^{4}$ En 2004, Wal-Mart ocupaba el tercer lugar entre las 50 mayores empresas transnacionales con operaciones en América Latina, solo superado por General Motors y Telefónica de España, y Carrefour se hallaba en el puesto número 13 (CEPAL, 2006, p. 56).

Durante este período, la expansión hacia las economías latinoamericanas de menor tamaño fue más limitada, siendo Royal Ahold prácticamente el único actor relevante en este proceso. En 1998, luego de entrar a Brasil, la firma holandesa se asoció con el grupo argentino Velox — dueños de las cadenas de supermercados Disco y Santa Isabel—y logró simultáneamente acceder a los mercados de Argentina, Chile, Paraguay y Perú. Al año siguiente, mientras comenzaba un ambicioso proceso de crecimiento en Estados Unidos, Royal Ahold colocó su atención en América Central. Para ello, y utilizando la misma estrategia que había aplicado en el Cono Sur, concretó una sociedad con la firma guatemalteca La Fragua, la que, además, ya tenía operaciones en El Salvador y Honduras. Posteriormente, amplió la asociación a la Corporación de Supermercados Unidos (CSU) de Costa
Rica, creándose la mayor red de supermercados de la subregión: Central America Retail Holding Company (CARHC).$^{5}$ En 2002, Royal Ahold asumió el control de las operaciones en América del Sur. No obstante, a principios del año siguiente, el grupo holandés tuvo graves problemas financieros y confesó públicamente irregularidades contables. En estas circunstancias y frente al deterioro de la situación económica en el Cono Sur, Royal Ahold anunció su decisión de abandonar América Latina, abriendo nuevos espacios para otras compañías que deseaban ampliar su presencia en la región. De este modo, los activos latinoamericanos más valiosos de Royal Ahold quedaron en manos de sólo dos empresas: Wal-Mart y el emergente grupo chileno Cencosud $^{6}$ (cuadro 3).

Como lo muestra la experiencia de Royal Ahold, para las grandes compañías de comercio minorista la expansión hacia el exterior no ha sido fácil, ya que el éxito en el país de origen no garantiza buenos resultados en el ámbito internacional (Bianchi y Ostalé, 2004, p. 3). Asimismo, las "ventanas de oportunidad" que se abrían

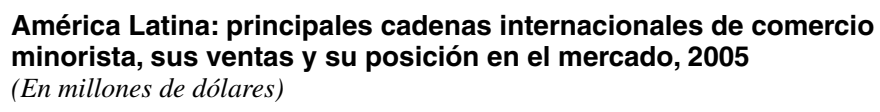

\begin{tabular}{|c|c|c|c|c|c|c|c|c|}
\hline & \multicolumn{4}{|c|}{ Líderes regionales } & \multicolumn{4}{|c|}{ Operadores emergentes } \\
\hline & \multicolumn{2}{|c|}{ Wal-Mart Stores } & \multicolumn{2}{|c|}{ Carrefour } & \multicolumn{2}{|c|}{ Cencosud } & \multicolumn{2}{|c|}{ Falabella } \\
\hline & Ventas & Posición & Ventas & Posición & Ventas & Posición & Ventas & Posición \\
\hline Argentina & $\ldots$ & $\ldots$ & 538 & 4 & 1743 & 1 & 144 & $\ldots$ \\
\hline Brasil & 5032 & 3 & 5394 & 2 & - & - & - & - \\
\hline Chile & - & - & - & - & 4915 & 1 & 3854 & 2 \\
\hline Colombia & - & - & 751 & 3 & - & - & - & - \\
\hline México & 15518 & 1 & $\mathrm{a}$ & - & - & - & - & - \\
\hline Perú & - & - & - & - & - & - & 404 & 3 \\
\hline Centroamérica & 2200 & 1 & - & - & - & - & - & - \\
\hline
\end{tabular}

Fuente: elaboración propia basada en datos de las compañías y de América economía (2006).

a En marzo de 2005, Carrefour vendió sus activos en México a la cadena local Chedraui, en un monto estimado de 500 millones de dólares.

\footnotetext{
${ }^{4}$ En 1995, Wal-Mart ingresó al mercado brasileño mediante una asociación con la cadena local Lojas Americanas para abrir un par de tiendas de descuento. Dos años después, la sociedad se disolvió y la compañía estadounidense inició un lento proceso de crecimiento orgánico, abriendo 25 nuevos locales. En el período reciente, el proceso se aceleró considerablemente a través de nuevas adquisiciones a algunos de sus mayores competidores globales. En marzo de 2004, Wal-Mart compró la cadena Bompreço por unos 300 millones de dólares a la compañía holandesa Royal Ahold, incorporando 118 locales en el noreste brasileño. Además, en diciembre de 2005, WalMart pagó 748 millones de dólares por las operaciones brasileñas de la empresa portuguesa Sonae; se posicionó así como la tercera cadena
}

de comercio minorista en el país, con 295 tiendas en 17 de los 26 estados brasileños, detrás de Carrefour y de la Companhia Brasileira de Distribuiçao (CBD), que tiene el respaldo del grupo francés Casino (The Wall Street Journal Americas, 2005).

${ }^{5}$ Royal Ahold tenía el control del 33,3\% de CARHCO, la que a su vez poseía el $85 \%$ de La Fragua y el $100 \%$ de CSU. En 2005, CARHCO operaba 363 tiendas en Costa Rica (124),Guatemala (120), El Salvador (57), Honduras (32) y Nicaragua (30).

${ }^{6}$ Wal-Mart adquirió la cadena brasileña Bompreço y la participación de Royal Ahold en la red centroamericana de supermercados CARHCO. Por otro lado, Cencosud compró la cadena Santa Isabel en Chile y los supermercados Disco en Argentina. 
en países en desarrollo llevaban asociados altos grados de incertidumbre, debido a la rápida saturación de los mercados internos y a su inestabilidad (gráfico 2). América Latina no fue la excepción, y al igual que Royal Ahold, otros grandes operadores internacionales decidieron abandonar la región. Entre los casos más emblemáticos destacan las salidas de The Home Depot de Argentina y Chile, y de Carrefour de Chile y México. En la mayoría de estas situaciones, los operadores internacionales no fueron capaces de adaptar sus formatos y prácticas a las características de los mercados locales, y enfrentaron problemas que no lograron anticipar, como dificultades con los proveedores, gustos de los consumidores y una agresiva competencia por parte de las cadenas locales ya establecidas.

En síntesis, los operadores internacionales dominantes, Wal-Mart y Carrefour, han concentrado sus esfuerzos en consolidar su posición en los principales mercados regionales. En el período reciente, han buscado ampliar su presencia hacia mercados de menor tamaño, con resultados agridulces. En general, en las economías más pequeñas, la consolidación se ha dado entre empresas locales, las que han ido incorporando algunas de las mejores prácticas y formatos desarrollados por los operadores globales. En este sentido, la experiencia de Chile es paradigmática, ya que las cadenas locales opusieron una férrea resistencia a los líderes globales, consolidaron su posición en el mercado interno, y luego se animaron a explorar nuevas oportunidades de negocios en los países vecinos. Esto último resulta especialmente interesante, ya que ni siquiera las grandes cadenas mexicanas -Organización Soriana, Controladora Comercial Mexicana, Grupo Gigante y el Grupo Elektra-, que le han dado dura competencia a Wal-Mart, han podido ampliar sus actividades hacia el exterior en un grado significativo.

\section{III}

\section{La presencia en América Latina del modelo de comercio minorista integrado}

En Chile, la industria del comercio detallista es uno de los sectores más dinámicos de la economía, en permanente evolución y con alto grado de competencia. Esto la transformó en el mercado más atractivo de América Latina (gráfico 3). En los últimos años, se ha registrado una tendencia hacia la consolidación de los diferentes formatos del sector que compiten por captar las preferencias de los consumidores: supermercados, cadenas de especialidad - farmacias, mejoramiento del hogar y construcción - y tiendas por departamento. También se ha hecho explícita una mayor diversificación de las fuentes de ingresos, básicamente a través del otorgamiento de crédito a los clientes, y la ampliación de la oferta de productos en un solo lugar con el propósito de captar un mayor número de consumidores (servicios bancarios, seguros y viajes). Muchos de estos cambios se llevaron a cabo en medio de profundas transformaciones de las principales compañías del sector, en especial, la transición desde empresas familiares a firmas con gestión profesional y su conversión en sociedades anónimas abiertas, lo que les ha permitido transar sus acciones en los mercados de capital, tanto en Chile como en el exterior.
Con la apertura de la economía y el incremento de la competencia por la llegada de los primeros operadores internacionales, las empresas de comercio minorista llevaron a cabo una exitosa estrategia defensiva. En primer lugar, estudiaron en forma anticipada a las mayores empresas de la industria del ámbito internacional, copiaron algunos de sus modelos y prácticas de negocios e identificaron y eliminaron sus falencias, para adaptarlos al mercado local. Asimismo, contrataron a ejecutivos vinculados a estas compañías e incorporaron nuevos productos y servicios. Por otro lado, las empresas extranjeras subestimaron la capacidad de reacción de las firmas locales y tuvieron que abandonar el mercado interno $^{7}$ (Bianchi y Ostalé, 2004). Así, en esta actividad

\footnotetext{
${ }^{7}$ En 1999, luego de cinco años de operación sin obtener ganancias, la mayor cadena estadounidense de tiendas por departamentos, J.C. Penney, vendió sus activos al competidor local: Almacenes París. En 2001, tres años después de iniciar sus actividades, la tienda de mejoramiento del hogar más grande del mundo, The Home Depot, decidió vender sus operaciones a su socio local, Falabella. En 2003, luego de cinco años de presencia en el país, la mayor cadena de supermercados del mundo, Carrefour, vendió sus locales al operador local D\&S. Finalmente, ese mismo año Cencosud adquirió las operaciones de Royal Ahold en Chile.
} 
ha surgido un grupo de empresas que han desarrollado ventajas competitivas, lo que les ha permitido alcanzar una presencia significativa en el mercado local, frustrar los intentos de operadores internacionales por ingresar al mercado chileno e iniciar procesos de internacionalización hacia los países vecinos (cuadro 4).

El negocio financiero es una de las mayores peculiaridades del comercio minorista en Chile. ${ }^{8}$ Las empresas chilenas fueron pioneras en la entrega de créditos de consumo. El desarrollo del sector ha estado estrechamente vinculado al otorgamiento de crédito a los clientes, lo que se ha potenciado con la creación de entidades financieras propias: Banco Falabella (1998), Banco Ripley (2003) y Banco París (2004). De hecho, satisfacer la demanda de crédito de sus clientes se ha convertido en una fuente adicional de ingresos y en un factor clave de la rentabilidad de estas compañías. Así, se potencia el negocio comercial y el éxito de este aumenta los niveles de crédito, produciéndose una sinergia importante entre ambos negocios (Falabella, 2004b, p. 27). Incluso, para momentos de desaceleración de la economía, el negocio de crédito podría cobrar más importancia, dado que las personas preferirían comprar a mayores plazos. En la actualidad, el negocio financiero representa entre $7 \%$ y $10 \%$ de los ingresos totales para Cencosud y Falabella, y cerca del 25\% para Ripley, que aún no está en el segmento de supermercados. Asimismo, estas compañías disponen de información respecto de sus clientes — hábitos de consumo y capacidad de en- deudamiento-, lo que les permite definir estrategias de comercialización y optimizar la composición de su mercadería y actividades de promoción. En la actualidad, se estaría concretando una estrategia orientada a la fidelización de la cartera más que a la captación de nuevos clientes. Así, se podrían seguir aumentando las colocaciones a través de más préstamos a los mejores clientes, sin acrecentar necesariamente el riesgo. ${ }^{9}$

La emisión de tarjetas de crédito de casas comerciales había venido operando sin demasiadas restricciones, lo que llevó en algunos casos a reclamos por parte de los usuarios. En estas circunstancias, en abril de 2006 entró en vigencia una nueva normativa que regula la operación y uso de las tarjetas de crédito no bancarias y entrega su fiscalización a la Superintendencia de Bancos e Instituciones Financieras (SBIF). ${ }^{10}$ Pese a que estos cambios en el marco regulatorio podrían afectar la capacidad de generar flujos operacionales, al parecer, las compañías del rubro se están adaptando con rapidez a este escenario más restrictivo. Para ello han incorporado mejoras en los modelos de predicción del perfil crediticio y han hecho más exigentes las políticas de provisión.

En Chile, en ausencia de operadores internacionales, las compañías locales han mantenido una aguda competencia, desde los hipermercados hasta los más novedosos formatos de tiendas por conveniencia. La estabilidad y crecimiento de la economía y la fuerte expansión del consumo permitieron que las empresas líderes siguieran creciendo sin mermas importantes en

Chile: principales grupos de comercio minorista y su participación de mercado, 2005 (En porcentajes)

\begin{tabular}{|c|c|c|c|c|}
\hline Grupo & Tiendas por departamento & Mejoramiento del hogar & Supermercados & Farmacias \\
\hline Falabella & 40 & 21 & 3 & - \\
\hline Cencosud & 29 & 5 & 25 & - \\
\hline Ripley & 31 & - & - & - \\
\hline $\mathrm{D} \& \mathrm{~S}$ & - & - & 35 & 4 \\
\hline Farmacias Ahumada (FASA) & - & - & - & 30 \\
\hline Salcobrand & - & - & - & 27 \\
\hline Cruz Verde & - & - & - & 34 \\
\hline Otros & 0 & 74 & 37 & 5 \\
\hline Total & 100 & 100 & 100 & 100 \\
\hline
\end{tabular}

Fuente: elaboración propia con información de las compañías.

\footnotetext{
${ }^{8}$ Esta estrategia ya había sido utilizada por compañías estadounidenses. No obstante, en Chile resultó particularmente exitosa, dado que el objetivo de las tarjetas de crédito de las grandes tiendas fueron los consumidores de menores ingresos, segmento claramente no cubierto por la banca tradicional.
}

\footnotetext{
${ }^{9}$ En diciembre de 2005, las principales empresas de comercio minorista tenían colocaciones por más de 3.150 millones de dólares: Falabella, 1.072 millones de dólares; Ripley, 907 millones de dólares; Cencosud, 428 millones de dólares; D\&S, 374 millones de dólares, y La Polar, 374 millones de dólares (La Segunda, 2006).

${ }^{10}$ Con la nueva normativa, los clientes que tengan algún problema con su tarjeta, ya sea irregularidades en los cargos efectuados por
} 


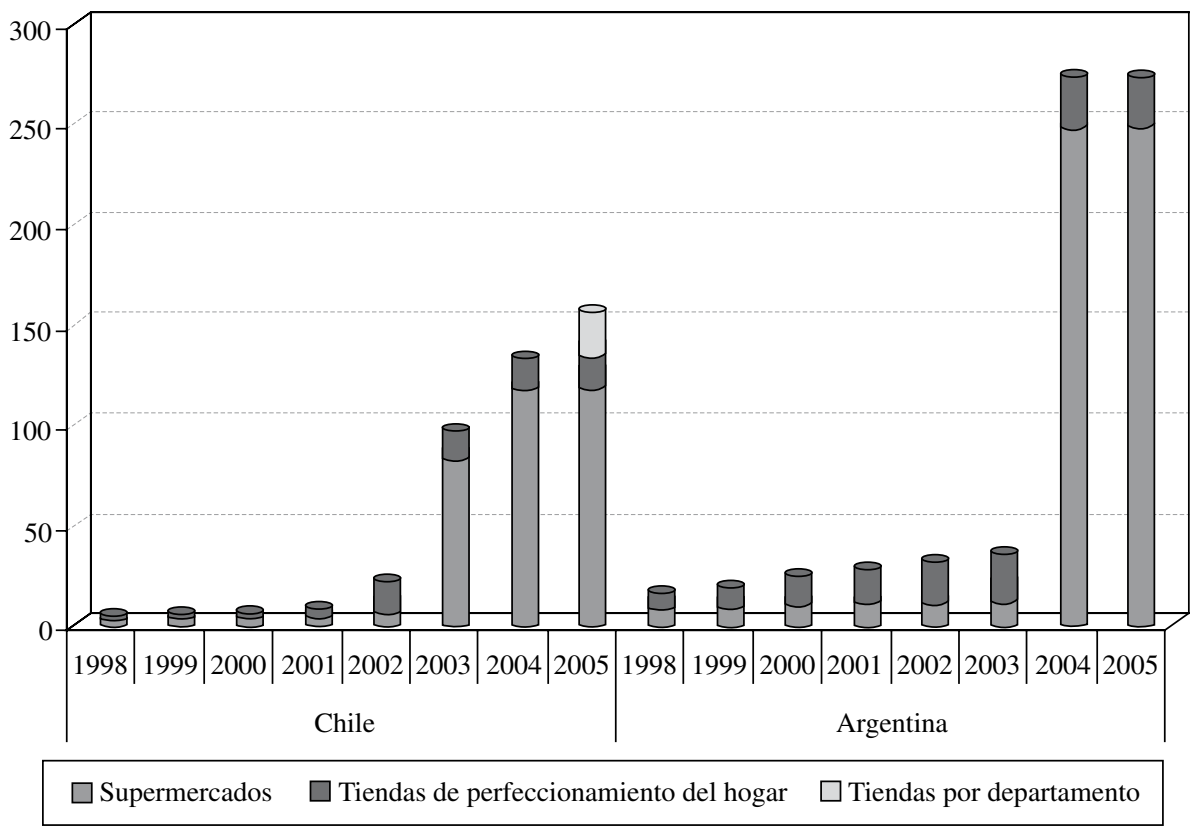

Fuente: elaboración propia basada en información de Cencosud.

sus participaciones de mercado. No obstante, al producirse las primeras muestras de saturación, las cadenas chilenas buscaron nuevas oportunidades de crecimiento en el exterior.

La pionera en la expansión internacional fue Cencosud. En el decenio de 1980 inauguró dos centros comerciales — con hipermercados Jumbo- en Buenos Aires, donde destacaba Unicenter, el mayor de su tipo en Argentina. Estas primeras incursiones marcaron lo que sería el patrón de la internacionalización de Cencosud: un fuerte desarrollo inmobiliario - construcción y gestión de centros comerciales- en conjunto con una activa participación en actividades de comercio minorista, particularmente en el área de supermercados, a las que luego agregaría tiendas para el mejoramiento del hogar. En 1993, la compañía introdujo simultáneamente en Chile y Argentina una nueva línea de negocios, con la creación de tiendas para el mejoramiento del hogar y la construcción, bajo la marca Easy. A partir de ese

concepto de comisiones o anomalías en la seguridad de las tarjetas, podrán presentar reclamos a la SBIF o al Servicio Nacional del Consumidor. Las empresas están obligadas a informar a sus clientes el concepto por el cual se cobran los intereses, la tasa aplicable, la base de cálculo y el período comprendido. momento y hasta 1998, la expansión de Cencosud en Buenos Aires fue especialmente dinámica, llevando a construir y gestionar siete nuevos centros comerciales, con locales Jumbo y Easy en todos ellos. En el caso de Easy, la estrategia de penetración fue aún más amplia, ya que cerca de la mitad de las tiendas fueron colocadas fuera de los centros comerciales administrados por Cencosud. De este modo se implementó una estrategia de generación de fuertes sinergias entre las distintas líneas de negocios de la compañía, centrada especialmente en Argentina (gráfico 4).

En el mismo período, al igual que Cencosud, la cadena de tiendas por departamentos Falabella fue hacia Argentina, pero con una estrategia bastante más conservadora. En 1993, Falabella abrió su primera tienda en la ciudad fronteriza de Mendoza, cuyos habitantes tenían conocimiento de la empresa debido al intenso intercambio turístico entre ambos países. La compañía visualizó una oportunidad de crecimiento en Mendoza con un menor riesgo al que hubiera significado ir directamente a Buenos Aires (Bianchi, 2002, p. 6). Con esta primera operación, Falabella se convirtió en la única cadena de tiendas por departamentos que operaba en el mercado argentino (Falabella, 2004b, p. 37). 
A pesar de esta posición privilegiada, los resultados no fueron todo lo exitosos que se esperaba. Falabella enfrentó un entorno complejo, donde las normas legales, las preferencias y hábitos de los consumidores y las facilidades para la importación de productos eran muy distintos a los que existían en Chile. No obstante, la compañía continuó con su expansión en Argentina con dos nuevas tienda, en San Juan (1994) y Córdoba (1997), buscando generar economías de escala que permitieran rentabilizar el negocio (Bianchi, 2002, p. 6). Sin embargo, la gran oportunidad para consolidarse en el mercado argentino llegó un poco después, aprovechando la remodelación que hizo Cencosud del centro comercial Unicenter. Así, Falabella ingresó como segunda tienda ancla de ese centro comercial, sumándose a Jumbo, y estableció presencia en Buenos Aires. Asimismo, y como una manera de promover el consumo en las tiendas por departamentos, introdujo su tarjeta de crédito CMR, y otros servicios como su agencia de viajes. Con el otorgamiento de crédito, los resultados de la empresa comenzaron a mejorar, lo que generó grandes expectativas respecto al futuro crecimiento de Falabella en Argentina (Falabella, 2000, p. 17).

Con la experiencia y las dificultades experimentadas en Argentina, Falabella reformuló su estrategia para abordar otros mercados, poniendo mayor énfasis en las idiosincrasias locales. En 1995, Falabella ingresó a Perú —estimulado por las auspiciosas perspectivas de crecimiento de la economía— mediante la adquisición de la cadena de tiendas por departamentos SAGA (Sociedad Andina de Grandes Almacenes), una empresa colombiana de amplio reconocimiento en ese país y con dos locales en la ciudad de Lima. La compañía comenzó a operar bajo el nombre de SAGA Falabella, conservando la administración local e incorporando los procesos y mejores prácticas aplicados en Chile (Bianchi, 2002, p. 7). Así, la buena posición de la marca SAGA, el conocimiento del mercado que tenían los antiguos controladores, la existencia de una cultura de compras en tiendas por departamentos y el hecho de ser considerado por el consumidor peruano como un actor local, permitió que Falabella rápidamente lograra resultados positivos (Falabella, 2004b, p. 38). Al igual que en Argentina, estos fueron potenciados con la introducción de la tarjeta de crédito CMR, la agencia de viajes y la oferta de seguros.

Dada la experiencia de Falabella, uno de sus principales competidores en Chile, Ripley, inició su proceso de internacionalización directamente en Perú en 1997. El nuevo concurrente, emulando las características del mercado chileno, inauguró su primer local en Lima en el Jockey Plaza Shopping Center, donde Falabella también estaba presente. En Perú, Ripley buscó consolidar su imagen corporativa entre los consumidores de mayores ingresos, para luego abordar segmentos de menor poder adquisitivo.

Entre 1996 y 1998, para enfrentar la nueva situación, Falabella amplió y remodeló los locales existentes, abrió dos nuevas tiendas en Lima e inauguró un centro de distribución. Además, buscó mantener una buena relación con sus proveedores peruanos (casi el $50 \%$ de sus compras eran locales) y a la vez conservar una estrecha coordinación con el área de compras de Chile, como una forma de crear sinergias en las compras por volumen a los proveedores extranjeros (Bianchi, 2002, p. 8).

Sin embargo, la situación económica en Perú comenzó a deteriorarse, afectando los resultados de las filiales de ambas compañías chilenas en ese país. En este contexto, Ripley y Falabella iniciaron una nueva fase de expansión, pero con cambios importantes en sus estrategias. En el 2000, Ripley introdujo un nuevo formato de tiendas (Max) de autoservicio y bajos precios. Esta estrategia le permitió abordar segmentos de la población de Lima donde aún no había entrado su competidor. Por su parte, Falabella, también inauguró tiendas de menor formato (SAGA Falabella Express), pero enfocadas en explorar la potencialidad de la compañía en el interior del país. Así, a través de una tienda de pequeñas proporciones y una selección ajustada de mercaderías, la empresa buscó identificar las necesidades y preferencias de los consumidores de la zona norte del país, e introducir la tarjeta de crédito CMR. En un breve período, Falabella abrió locales en Trujillo — la ciudad más importante del norte del país-, Chiclayo, Piura y Arequipa.

Sumado a las dificultades en Perú, el fuerte deterioro de la economía argentina afectó los planes de Falabella y Cencosud. La primera congeló las inversiones y anunció que no abriría nuevas tiendas en Argentina, concentrándose en el mejoramiento de la gestión comercial y la eficiencia de sus operaciones (Falabella, 2001, p. 19 y El Mercurio, 2002). En este sentido, una de las medidas más importantes que adoptó la empresa chilena en Argentina fue reducir en breve lapso el porcentaje de mercadería importada, reemplazándola por productos de proveedores locales - los que se adecuaban mejor a las preferencias de los argentinos-, lo que le permitió obtener una ventaja competitiva importante (Falabella, 2004b, p. 37). Además, Falabella buscó mejorar su estrategia comunicacional y aprovechar con mayor fuerza las economías de escala que se generaban en conjunto con Perú y Chile (Falabella, 2001, p. 19). Finalmente, el formato de tiendas por departamentos resultó muy conveniente y flexible para los consumidores argentinos 
CUADRO 5

Cencosud: centros comerciales en Argentina, 2005

\begin{tabular}{|c|c|c|c|c|}
\hline Inauguración & Centro comercial & $\begin{array}{l}\text { Superficie } \\
\text { arrendable } \\
\qquad\left(\mathrm{m}^{2}\right)^{\mathrm{a}}\end{array}$ & Ubicación & Descripción \\
\hline 1988 & Unicenter & 91771 & Martínez, Buenos Aires & $\begin{array}{l}\text { Jumbo, Falabella, } 287 \text { tiendas, Aventura, } \\
\text { Food Court, } 14 \text { cines }\end{array}$ \\
\hline 1993 & Lomas Center Factory & 33675 & Lomas de Zamora, Buenos Aires & Jumbo, Easy, 50 tiendas, Aventura \\
\hline 1994 & San Martín Factory & 32729 & San Martín, Buenos Aires & Jumbo, Easy, 31 tiendas, Aventura \\
\hline 1996 & Centro Comercial Palermo & 29699 & Capital Federal & Jumbo, Easy, 43 tiendas \\
\hline 1997 & Quilmes Factory & 44132 & Quilmes, Buenos Aires & $\begin{array}{l}\text { Jumbo, Easy, } 47 \text { tiendas, Aventura, } \\
\text { Food Court, } 12 \text { cines }\end{array}$ \\
\hline 1997 & Plaza Oeste Shopping & 41634 & Morón, Buenos Aires & $\begin{array}{l}\text { Jumbo, Easy, } 138 \text { tiendas, Aventura, } \\
\text { Food Court, } 8 \text { cines }\end{array}$ \\
\hline 1998 & Las Palmas del Pilar & 49581 & Pilar, Buenos Aires & Jumbo, Easy, 102 tiendas \\
\hline 2000 & Portal del Escobar & 32740 & Escobar, Buenos Aires & Jumbo, Easy, 24 tiendas \\
\hline 2000 & Portal de La Patagonia & 33813 & Neuquén & Jumbo, Easy, Food Court, 40 tiendas \\
\hline 2001 & Portal de Los Andes & 32563 & Godoy Cruz, Mendoza & Jumbo, Easy, 30 tiendas \\
\hline 2004 & Portal Rosario & 55000 & Rosario & Jumbo, Easy, 160 tiendas, Food Court, cines \\
\hline
\end{tabular}

Fuente: elaboración propia con información de Cencosud.

a Incluye locales Jumbo y Easy.

en un contexto de recesión económica, pues ellos podían hacer sus compras utilizando la tarjeta de crédito CMR (Falabella, 2004a, p. 14).

Por otro lado, Cencosud, a diferencia de Falabella, siguió creciendo pero concentró sus esfuerzos en la expansión hacia el interior de Argentina en el negocio inmobiliario, con centros comerciales un poco más pequeños (Neuquén y Mendoza), y con la ampliación de la red de tiendas Easy (cuadro 5). Además, en un contexto de profunda crisis económica, Cencosud vio una oportunidad, y mientras otros operadores importantes de la industria intentaban salir del país, la compañía chilena buscaba opciones para seguir creciendo. Aunque experimentó importantes caídas en sus ventas, claramente tenía confianza en la recuperación de la economía argentina (gráfico 5). En 2002, Cencosud concretó la compra en 105 millones de dólares de los cuatro locales que la cadena estadounidense The Home Depot poseía en Argentina (Cencosud, 2003, p. 15).

De este modo, Cencosud se transformó en uno de los mayores administradores de centros comerciales ${ }^{11} \mathrm{y}$ el líder de la industria de tiendas para el mejoramiento

${ }^{11}$ El mercado de centros comerciales en Argentina está compuesto básicamente por dos grandes operadores: Cencosud e IRSA-Alto Palermo Centros Comerciales. Ellos abarcan el 60\% del área bruta arrendable en este tipo de establecimientos comerciales. del hogar y construcción de Argentina (cuadros 5 y 6). Por otro lado, la devaluación obligó a Easy a sustituir importaciones e incorporar un mayor número de proveedores locales. ${ }^{12}$ Asimismo, a partir de esta situación surgió la oportunidad de incorporar productos a la filial en Chile, permitiendo aprovechar las sinergias por volumen de compra (Cencosud, 2004, p. 36).

A principios de la década del 2000, la difícil situación económica en Argentina y Perú frenó el ímpetu de la expansión internacional de las mayores empresas chilenas de comercio minorista. En cambio, estas se fortalecieron y crecieron en Chile, introduciendo cambios importantes en la estrategia de desarrollo de sus negocios. Frente a las limitaciones impuestas por el tamaño del mercado local, las compañías comprendieron que no se podía lograr una escala adecuada si se actuaba en un solo segmento de la industria, por lo que comenzaron a ampliar y diversificar su oferta, de manera de crear sinergias entre diferentes negocios relacionados. Así, mientras los operadores globales se especializaban y estandarizaban sus formatos, en Chile comenzó a surgir una nueva variante en la industria del comercio minorista: el comercio minorista integrado (retail integrado).

\footnotetext{
${ }^{12}$ Con anterioridad, cerca del $30 \%$ de los artículos que se vendían en las tiendas era de origen extranjero.
} 
GRÁFICO 5

Cencosud: ingresos de explotación, por segmento de negocio y país, 2001-2005

(En millones de pesos chilenos)

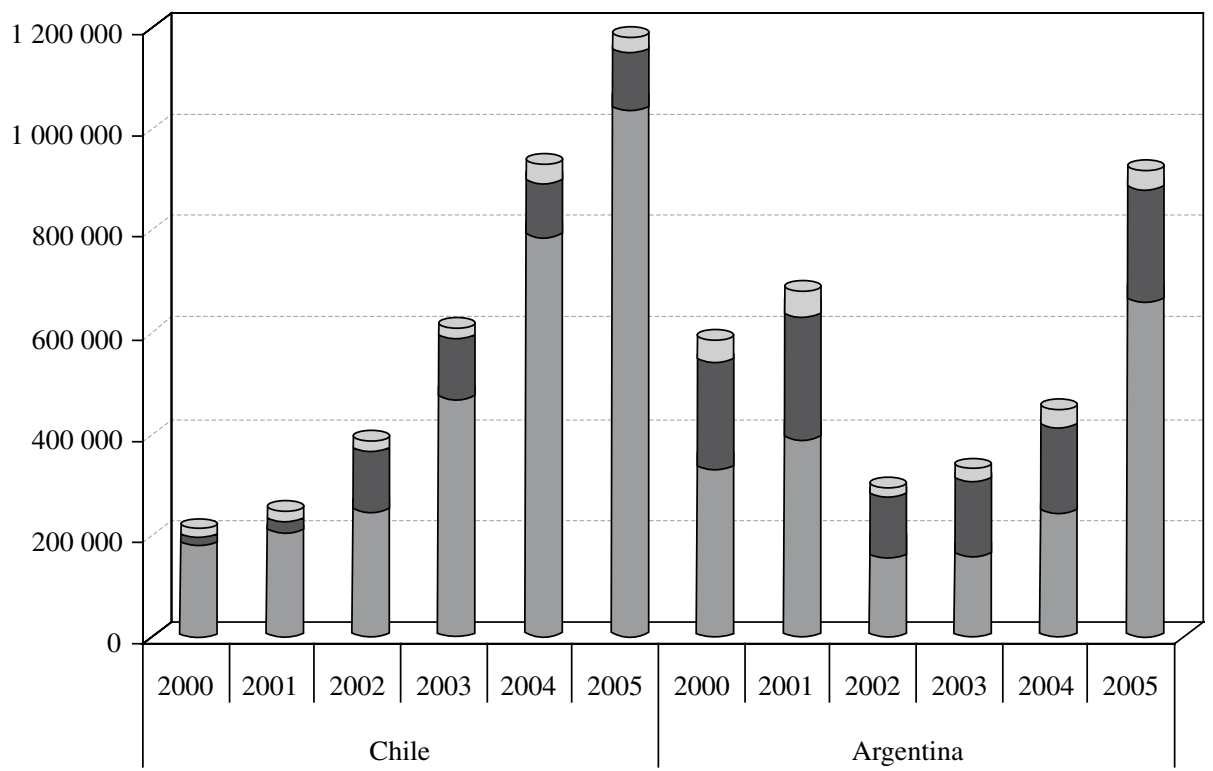

$\square$ Supermercados $\square$ Tiendas de perfeccionamiento del hogar $\square$ Centros comerciales

Fuente: elaboración propia con información de Cencosud.

CUADRO 6

Empresas de comercio minorista: número de tiendas, por segmento de negocios y país, 2000-2005

\begin{tabular}{|c|c|c|c|c|c|c|c|c|c|}
\hline & \multicolumn{3}{|c|}{ Falabella } & \multicolumn{3}{|c|}{ Cencosud } & \multicolumn{3}{|c|}{ Ripley } \\
\hline & 1998 & 2000 & 2005 & 1998 & 2000 & 2005 & 1998 & 2000 & 2005 \\
\hline \multicolumn{10}{|c|}{ Tiendas por departamentos } \\
\hline Chile & 26 & 29 & 33 & - & - & 21 & 14 & 23 & 31 \\
\hline Argentina & 4 & 5 & 6 & - & - & - & - & - & - \\
\hline Perú & 4 & 4 & 10 & - & - & - & 1 & 4 & 8 \\
\hline \multicolumn{10}{|c|}{ Mejoramiento del hogar } \\
\hline Chile & 2 & 5 & 54 & 2 & 3 & 16 & - & - & - \\
\hline Argentina & - & - & - & 8 & 14 & 26 & - & - & - \\
\hline Perú & - & - & 2 & - & - & - & - & - & - \\
\hline Colombia & - & - & 9 & - & - & - & - & - & - \\
\hline \multicolumn{10}{|c|}{ Supermercados } \\
\hline Chile & - & - & 11 & 3 & 4 & 119 & - & - & - \\
\hline Argentina & - & - & - & 8 & 10 & 248 & - & - & - \\
\hline Perú & - & - & 3 & - & - & - & - & - & - \\
\hline
\end{tabular}

Fuente: elaboración propia sobre la base de información de Falabella, Cencosud y Ripley.

Los primeros pasos en esta dirección los dio Falabella. A fines del decenio de 1990 ingresó al negocio de tiendas para el mejoramiento del hogar, en sociedad con la firma estadounidense The Home Depot, y adquirió el 20\% de la cadena Farmacias Ahumada (FASA), empresa especializada con una interesante estrategia de crecimiento. En 2001, Falabella adquirió la participación que tenía The Home Depot en la operación conjunta, creando HomeStore, y dos años después fusionó a HomeStore con Sodimac, la mayor empresa del rubro en el mercado chileno. Con esta operación potenció indirectamente la internacionalización de la compañía, 
puesto que Sodimac tenía presencia en Colombia. ${ }^{13}$ Posteriormente, Falabella se expandió hacia el segmento de supermercados, primero en Perú —a través de la creación de los hipermercados Tottus-, experiencia que rápidamente trasladó a Chile. ${ }^{14}$

Por otro lado, Cencosud no se quedó atrás y comenzó a implementar una estrategia con características similares. En primer término, buscó ampliar la cobertura geográfica y diversificar el formato de su cadena de supermercados en Chile, para lo cual adquirió varios operadores locales: Santa Isabel, Las Brisas y Montecarlo (Cencosud, 2005, p. 13). Luego, en marzo de 2005, Cencosud realizó su jugada más audaz, al adquirir Almacenes París, tercera cadena de tiendas por departamento del mercado chileno, detrás de Falabella y Ripley. ${ }^{15}$ De esta manera, al igual que Falabella, Cencosud logró conformar una oferta amplia en el negocio del comercio minorista, lo que le permitirá generar sinergias y complementariedades entre los activos de la compañía, particularmente con el negocio de crédito no bancario - Cencosud (Jumbo) y Almacenes París suman un total cercano a 4 millones de tarjetas de crédito- y con el Banco París.

De esta manera, Cencosud y Falabella estarían ganando varios años en el desarrollo de un modelo integrado de supermercados y tiendas por departamentos, una estrategia que ha llevado a cabo con éxito la cadena española El Corte Inglés. Asimismo, a pesar de que el concepto de comercio minorista integrado ha tenido su mayor impulso en el mercado interno, con el mejoramiento de la situación en varias economía latinoamericanas esta nueva estrategia comenzó a trasladarse rápidamente a las operaciones en el exterior. Así, Falabella y Cencosud han mostrado un gran interés por seguir expandiéndose hacia segmentos o "nichos" relativamente poco desarrollados en otros países de la región.

Falabella, en menos de dos años, ha reproducido con gran éxito su modelo de negocios en Perú. En este período ha abierto tres hipermercados Tottus, dos locales para el mejoramiento del hogar Sodimac Home Center —además de tener contemplado inaugurar otros seis más

\footnotetext{
${ }^{13}$ En 1994, los dueños originales de Sodimac formaron una empresa conjunta con el grupo local Corona para introducir la franquicia Homecenter en Colombia. Actualmente, Falabella mantiene el 35\% de la propiedad de la operación conjunta y gestiona ocho tienda, logrando cobertura nacional y consolidándose como el líder del sector en el país (Sodimac, 2005, p. 25).

${ }^{14}$ En 2004, Falabella ingresó al negocio de supermercados en Chile con la adquisición del $88 \%$ de Supermercados San Francisco, la tercera cadena del país, luego de pagar 62,5 millones de dólares.

15 El 31 de agosto de 2005, las juntas de accionistas de ambas entidades aprobaron la fusión de Cencosud y Almacenes París, siendo esta última sociedad absorbida por Cencosud.
}

CUADRO 7

Sector de comercio minorista: inversiones programadas, 2006-2010

(En millones de dólares)

\begin{tabular}{lcr}
\hline Empresa & Período & Monto \\
\hline Cencosud & $2006-2010$ & 1200 \\
Falabella & $2006-2009$ & 1130 \\
Ripley & $2006-2007$ & 551 \\
D\&S & $2006-2009$ & 800 \\
\hline
\end{tabular}

Fuente: elaboración propia con datos de informes de las compañías

en los próximos dos años (Sodimac, 2005, p. 24)—, y cuatro nuevas tiendas por departamentos SAGA Falabella (cuadro 6). En Argentina, espera tener un nuevo impulso con la apertura de dos tiendas por departamentos en la calle Florida, en el centro de Buenos Aires (La Nación, 2005 y Falabella, 2005, p. 20). En Colombia, planea abrir tres nuevos locales de Sodimac y cuatro tiendas por departamentos Falabella, formato que prácticamente no existe en el país. ${ }^{16}$ De hecho, Falabella anunció que invertiría en los siguientes cuatro años unos 1.130 millones de dólares (Falabella, 2006, p. 11) para duplicar sus puntos de venta en todos sus formatos en Chile, Argentina, Colombia y Perú (cuadro 7). Además, la compañía está buscando nuevas oportunidades en Ecuador y Venezuela (Business Latin America, 2005). Con ello, Falabella declaró explícitamente su objetivo de convertirse en un importante jugador regional. La compañía chilena, por lo tanto, se ha transformado en una de las diez compañía de comercio minorista de más rápido crecimiento en el mundo (Deloitte, 2006, p. 15).

Por otro lado, Cencosud, con los primeros signos de recuperación en Argentina, vio la oportunidad de ampliar su participación de mercado y mejorar la cobertura geográfica de sus operaciones en ese país, para lo cual adquirió la cadena de supermercados Disco — segunda en importancia en Argentina- a Royal Ahold, operador que enfrentaba graves dificultades. ${ }^{17}$ Así, muy pronto

\footnotetext{
16 Para ello pretende invertir unos 100 millones de dólares en conjunto con el grupo Corona, sus socios en Sodimac (El Mercurio, 2005a).

17 A principios de 2004 , Cencosud completó con éxito su primera colocación de acciones y American Depositary Receipts (ADR), equivalente al $21 \%$ de su propiedad, lo que le permitió recaudar fondos por 332 millones de dólares. Con estos recursos, unos meses después concretó un acuerdo con Royal Ahold para adquirir el 85\% de la propiedad de la segunda cadena de supermercados del país, Disco S.A., por un valor cercano a los 315 millones de dólares. Finalmente, y luego de múltiples conflictos judiciales, la operación se concretó, aunque sin que se pudiera concretar la fusión con Jumbo (El Clarín, 2005). Así, en un período especialmente difícil, luego de la compra de Disco y la remodelación de los locales de Jumbo — donde invirtió más de 500 millones de dólares_-, Cencosud se convirtió en el segundo
} 
comenzó a demostrar sus capacidades en Argentina, donde competía con los dos líderes globales, Wal-Mart y Carrefour, y a principios de 2005 registraba una participación de mercado de $22 \%$. Además, luego de la compra de Almacenes París, la compañía pretende potenciar la internacionalización de la tienda por departamentos, aprovechando la plataforma de centros comerciales que posee en Argentina. ${ }^{18}$ En 2010, Cencosud pretende duplicar sus ventas para superar los 10.000 millones de dólares anuales, y de este modo posicionarse como el cuarto operador más importante de la industria en América Latina, detrás de Wal-Mart, Carrefour y Casino. Con este propósito, la empresa chilena piensa invertir unos 1.200 millones de dólares, financiados básicamente con fondos propios. Además de crecer en Chile, Cencosud pretende ampliar en Argentina el número de tiendas Easy de 26 a 50 y establecer entre siete y nueve locales de Almacenes París (cuadro 7). En este período, desea entrar en un tercer país, y para ello está explorando oportunidades en Brasil, Colombia, México, Perú y Venezuela (La Tercera, 2006a).

Ripley tampoco se ha quedado atrás, y ha seguido buscando oportunidades para diversificar su negocio. En este sentido, Ripley podría reproducir la experiencia de Falabella en el rubro de supermercados en Perú y luego abordar el mercado chileno. Asimismo, la compañía ha anunciado que dará un renovado impulso a la expansión internacional. Para ello apunta a otros países latinoamericanos con potencial y de tamaño "abordable", entre los cuales destacan Colombia, Ecuador y Venezuela (El Mercurio, 2005b). No obstante, recientemente Ripley ha manifestado su interés de abordar mercados más grandes, como Brasil y México (La Tercera, 2006b). Para ello, Ripley tiene programadas inversiones por más de 550 millones de dólares (cuadro 7).

Asimismo, la experiencia chilena ha sido adoptada por otros operadores en América Latina. En Colombia, por ejemplo, Falabella y Carrefour se asociaron para gestionar un sistema de venta de crédito propio, mientras que la cadena local Carulla Vivero ha intentado lo mismo con Ripley (América economía, 2006a, p. 92). En este último caso se ha retrasado la concreción de la alianza, porque la cadena colombiana Almacenes

operador en el negocio de supermercados en Argentina (Cencosud, 2005, y Estrategia, 2004).

18 Al igual que en el caso de Jumbo y de Easy, Cencosud proyecta instalar una tienda de Almacenes París en cada uno de sus centros comerciales en el país vecino. Este proceso se iniciaría a comienzos de 2006, con la instalación de una tienda de Almacenes París en Unicenter en Buenos Aires, para competir con Falabella (La Nación, 2005).
Éxito podría adquirir parte de Carulla Vivero ( $\mathrm{La}$ Tercera, 2006b).

Con estos antecedentes, parece lógico pensar que las mayores compañías chilenas de comercio minorista deberían seguir ampliando su cobertura, tanto en los diferentes segmentos de la industria como en el ámbito geográfico. Con este propósito, ya han anunciado ambiciosos planes de inversión para los próximos años. En estas compañías, los planes de expansión pasada y futura han requerido una compleja ingeniería financiera, de modo de combinar fondos propios, créditos bancarios, bonos y emisiones de nuevas acciones, y así cumplir con las necesidades de financiamiento de este proceso. Con todo, presentan niveles aceptables y acotados de endeudamiento. La empresa que enfrentó mayores dificultades fue Cencosud, ya que luego de su agresivo plan de expansión reciente presentaba un abultado endeudamiento; no obstante, ha logrado mejorar con prontitud la situación. ${ }^{19}$

En resumen, los ingresos de las grandes cadenas chilenas de comercio minorista se han expandido de forma sostenida, estimulados por el crecimiento de la economía local y, en especial, por el comportamiento del consumo privado. Esto se refleja en los anuncios de voluminosas inversiones para los próximos años, en la continua inauguración de nuevos locales y en la ampliación de los convenios para el uso de los instrumentos de crédito. Así, estas compañías han consolidado y ampliado su participación en los mercados donde operan. Las grandes cadenas han ganado presencia a través de la adquisición de operadores menores, aumentando de manera significativa la concentración en el mercado interno. A pesar de esta tendencia, no hay evidencias claras de que se haya atentado contra la competencia. De hecho, en general, los consumidores han sido favorecidos por menores precios.

En este escenario, aún existen espacios para que las empresas líderes sigan creciendo, lo que indicaría que la industria está lejos de haber alcanzado su madurez. En esta dirección destacan dos tendencias centrales: i) la búsqueda de sinergias entre diferentes segmentos

\footnotetext{
${ }^{19}$ En enero de 2005 se aprobó un aumento de capital que sirvió para pagar parte de la compra de Almacenes París. Incluyendo los pasivos de Almacenes París, la deuda financiera de Cencosud alcanza a 1.156 millones de dólares, de los cuales un $40 \%$ tiene vencimientos en el corto plazo. En junio del mismo año, Cencosud vendió el 38,6\% de Disco y Jumbo en Argentina a varios fondos institucionales por 130 millones de dólares, y posteriormente concretó un plan de refinanciamiento de pasivos por 550 millones de dólares. Esta operación permitió alargar el perfil de vencimiento en más de $50 \%$ de los pasivos financieros de la empresa (Cencosud, 2006, p. 8).
} 
y formatos de la industria del comercio minorista en un mercado pequeño como el chileno, y ii) el intento de ampliación del mercado mediante selectivas y graduales estrategias de internacionalización. La primera de estas tendencias ha permitido que las empresas líderes se consoliden en el mercado interno, frenen la expansión de las cadenas internacionales, y acumulen conocimientos muy valiosos en el manejo de negocios relacionados, en especial, con un segmento financiero cada vez más importante. Por otro lado, con esta experiencia, las mayores empresas del rubro comenzaron a abordar con particular éxito algunos mercados externos, estableciéndose así un renovado potencial para las dimensiones del negocio. Asimismo, la experiencia internacional ha permitido que los operadores líderes asimilen nuevos elementos, como las idiosincrasias locales y la relación con proveedores, a sus estrategias generales. No obstante, también es cierto que la mayor exposición internacional significará el incremento de la competencia con los operadores globales, lo cual podría introducir mayor incertidumbre en la sustentación de estas estrategias por parte de las compañías chilenas.

\section{IV}

\section{Comercio minorista especializado: una trayectoria de éxito en mercados atomizados}

A diferencia de lo que sucede con las grandes empresas de comercio detallista que han crecido rápidamente, ampliando el ámbito de sus negocios y su cobertura geográfica, en Chile también se ha dado un caso interesante que posee una lógica totalmente contraria: la especialización en un segmento de la industria. Tal es el caso de algunas cadenas de farmacias y tiendas de mejoramiento del hogar, como Farmacias Ahumada (FASA) y Casa\&Ideas respectivamente. ${ }^{20}$

En cerca de 35 años, FASA pasó de ser una clásica farmacia tradicional hasta constituirse en la primera cadena de farmacias en América Latina y una de las diez más importantes del mundo, con operaciones en Chile, Perú, México y hasta hace poco tiempo Brasil (FASA, 2005, p. 7; Chain Drug Review, 2002). Además, ha sido una de las pocas compañías en el ámbito global que han logrado desarrollar una estrategia de internacionalización en este segmento del comercio minorista, donde destaca la británica Boots Group PLC.

En los últimos años, el mercado chileno de farmacias ha experimentado un intenso proceso de consolidación en un ambiente de alta competencia:

\footnotetext{
${ }^{20}$ La experiencia de Casa\&Ideas es más reciente y de menor alcance. En 1993 se inauguró la empresa Casa, con dos tiendas en Santiago de Chile; cinco años después fue reemplazada por Casa\&Ideas, con nueva imagen corporativa y un nuevo concepto del negocio: diseño accesible para todos. Tras tener gran éxito en Chile, en 2005 la empresa inició su expansión internacional con la inauguración de dos tiendas en Lima, Perú. Actualmente, Casa\&Ideas posee 26 tiendas en Chile y tres en Perú.
}

los tres principales operadores concentran más del $90 \%$ del mercado (véase el cuadro 4). A diferencia de sus competidores, FASA visualizó que la baja de la participación de las farmacias independientes y la consecuente consolidación de las cadenas iba a traducirse en menores oportunidades de crecimiento en Chile. En este escenario, inició un activo proceso de internacionalización, buscando nuevos mercados que le permitan crecer rentablemente y aprovechar las sinergias que le dan su tamaño y experiencia (FASA, 2005, p. 7). De hecho, abordó mercados altamente atomizados y fragmentados, lo que le permitió incrementar rápidamente su participación mediante el aprovechamiento de ventajas de costos asociadas al mayor volumen de negocios, a la implementación de mejoras tecnológicas y logísticas y a campañas de comercialización (FASA, 2002, p. 29; FASA, 2003, p. 49).

En 1996 se inició el proceso de internacionalización de FASA, que ingresó al mercado peruano y creó la cadena de farmacias Boticas FASA S.A., en conjunto con inversionistas locales. En el año 2000, FASA en conjunto con AIG Capital Partners Inc. adquirieron en 25 millones de dólares el 77\% de Drogamed, la principal cadena de farmacias del estado de Paraná, Brasil. Un año más tarde, con el propósito de tomar el control total de sus filiales en Perú y Brasil, FASA compró el 15\% de Boticas FASA y el 23\% de Drogamed, esta última en conjunto con AIG. A principios de 2005, FASA compró a AIG el $35 \%$ restante de Drogamed y con ello pasó a controlar el 100\% de la compañía (gráfico 6). 
GRÁFICO 6

Farmacias Ahumada: número de locales, por país, 1998-2005

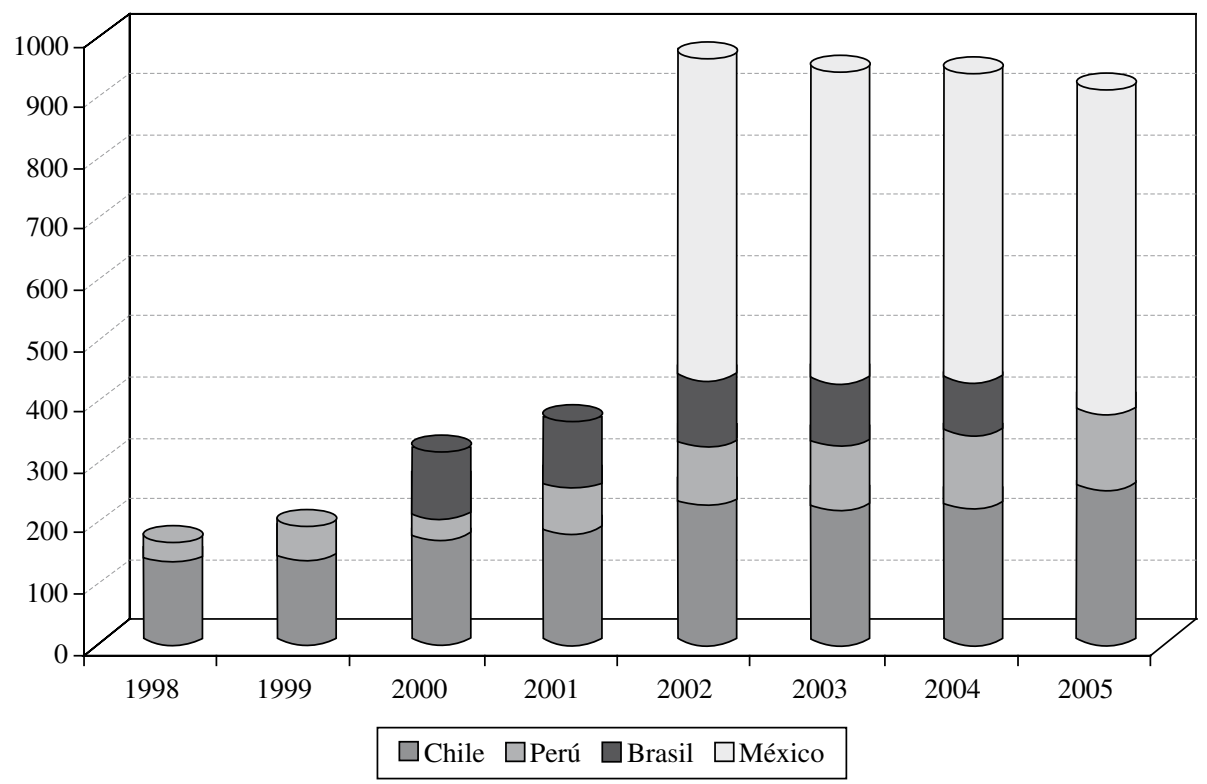

Fuente: elaboración propia con información de FASA.

En diciembre de 2002, FASA tomó el control accionario de la sociedad mexicana Far-Ben S.A. de C.V., mediante la suscripción y pago de un aumento de capital por 45 millones de dólares. La cadena mexicana atravesaba por una profunda crisis y necesitaba un socio estratégico para cambiar su situación financiera (América economía, 2006b, p. 46). En 2003, FASA consolidó sus operaciones, incorporando exitosamente a Farmacias Benavides, en Monterrey, México. Esto implicó duplicar la operación en términos de ventas, clientes y número de locales (véase el gráfico 4).

Así, aplicando distintas estrategias de internacionalización según el mercado de que se trate — desde operaciones totalmente nuevas en Perú (Boticas FASA) hasta adquisiciones de cadenas en Brasil y México (Drogamed y Farmacias Benavides)—, FASA logró dar un giro sustancial a sus operaciones en un plazo récord. Actualmente, después de más de ocho años de expansión internacional, obtiene del exterior más de un $60 \%$ de los ingresos consolidados de sus operaciones. Además, más del $71 \%$ de sus clientes se encuentra fuera de las fronteras de Chile.

No obstante, el proceso de expansión internacional de FASA no estuvo ajeno a dificultades, particularmente en Brasil. De hecho, la operación en ese país originó en gran medida el deterioro de las utilidades de la compañía, las que cayeron de 10,5 millones de dólares a 2,5 millones de dólares entre el 2001 y el 2002. Lo fragmentado del mercado brasileño hacía difícil el funcionamiento de una cadena con las características de FASA y, a pesar de los fuertes aportes de capital, las deudas se incrementaban y las operaciones no repuntaban. Además, la competencia en Chile se intensificaba, lo que la habría llevado a perder seis puntos de participación de mercado entre el 2003 y el 2005 (América economía, 2006b, p. 47). En estas circunstancias, FASA decidió salir de Brasil. En enero de 2006, después de cinco años de pérdidas, vendió su filial brasileña a quien era el presidente ejecutivo de Drogamed. La compleja regulación, altos impuestos y comisiones, unidos a la informalidad y las dificultades para acomodarse a la idiosincrasia local, hicieron que la actividad en Brasil, el sexto mayor consumidor de productos farmacéuticos del mundo, se tornara una pesadilla (Qué Pasa, 2006).

En síntesis, frente a la competencia intensa y persistente en el mercado chileno, FASA decidió ampliar sus operaciones en el exterior, apoyada en la experiencia acumulada en Chile y lo poco desarrollados que estaban los mercados externos. Salvo la experiencia de Brasil, los resultados han sido exitosos, situando a la compañía entre las pocas del mundo que han logrado internacionalizar sus operaciones en el comercio minorista de productos farmacéuticos. 


\section{V}

\section{Conclusiones}

Las empresas chilenas de comercio minorista han logrado construir importantes ventajas competitivas sustentadas en un modelo de negocios que se basa en las sinergias obtenidas por la operación conjunta de una serie de actividades relacionadas, que se halla fuertemente orientado al cliente y que tiene una poderosa dimensión financiera. Esta estrategia proporcionó a dichas empresas una sólida base en el mercado local, que les permitió abortar las arremetidas de algunos de los grandes operadores internacionales por ingresar a uno de los destinos más atractivos para la industria del comercio minorista entre las economías emergentes. El desarrollo de esta fórmula de comercio minorista integrado fue el resultado directo de la intensa competencia en el mercado chileno, que por su tamaño limitado dificultaba la posibilidad de ser rentable operando en un solo segmento de la industria del comercio minorista. Las compañías chilenas, por lo tanto, fueron cerrando progresivamente el círculo del comercio minorista integrado, gracias a seis pilares básicos: las tiendas por departamentos, las tiendas de mejoramiento del hogar, los supermercados, la administración de tarjetas de crédito, los servicios financieros prestados a través de un banco propio, y el negocio inmobiliario. Así, la clave del éxito fue la combinación de las mejores prácticas de los líderes internacionales con el conocimiento local, una oferta diversificada que incluye servicios bancarios y la capacidad de supervivencia en un mercado altamente competitivo.

Tras el éxito en el mercado local, y anticipándose a los primeros signos de saturación, las compañías de comercio minorista vieron en la expansión internacional la mejor opción para iniciar una trayectoria de crecimiento sustentable. La internacionalización de estas empresas ha sido gradual y acotada a los países vecinos, lo que les ha permitido ir asimilando sin grandes traumas la experiencia de operar en otros mercados. Asimismo, algunos de los elementos desarrollados en el mercado chileno han sido emulados por otros operadores regionales.

En su expansión internacional, las empresas han aplicado los elementos centrales de las estrategias que han desplegado en Chile. No obstante, también han efectuado algunas adaptaciones para lograr una buena aceptación y conocer de cerca la idiosincrasia y las necesidades de los consumidores locales. En este sentido destacan la búsqueda de socios locales, el estableci- miento de relaciones de largo plazo con proveedores y el empleo preferente de personal del país donde se realizan las inversiones. Una parte importante de estos cambios tuvo lugar durante períodos de crisis en los países donde tenían operaciones. Esta situación permitió aprovechar nuevas oportunidades y adquirir activos de empresas transnacionales que no lograron superar la intensidad de la crisis y entender las particularidades de los consumidores locales.

En el último tiempo los mayores operadores locales, particularmente en el área de supermercados, han enfrentado nuevos desafíos en el mercado interno. Por un lado, las limitaciones impuestas por el Tribunal de Derecho de la Libre Competencia (TDLC) para seguir creciendo en el mercado chileno mediante la adquisición de otras cadenas de menor tamaño, y la regulación de las relaciones de esos operadores con sus proveedores, contribuirán a vigilar la concentración del mercado y evitar conductas abusivas. Por otro lado, las nuevas normas impuestas por la Superintendencia de Bancos e Instituciones Financieras (SBIF) para las tarjetas de crédito que otorgan los operadores de comercio minorista supervisarán la emisión y uso de estos medios de pago no bancarios, impidiendo el cobro de intereses o cargos excesivos. En este nuevo escenario, a pesar de enfrentar mayores restricciones que en el pasado, las empresas locales no estarían en una situación particularmente compleja. De hecho, quizás algunas de ellas verán disminuir sus márgenes, pero incrementarán su eficiencia y mejorarán de forma significativa su relación con sus clientes y proveedores. Y sin duda podrían seguir mejorando sus niveles de gestión interna y evaluar con mayor entusiasmo la posibilidad de ampliar sus planes de expansión internacional.

También es cierto que el modelo desarrollado por las empresas chilenas sería aplicable a economías de tamaño intermedio, donde los grandes operadores internacionales, como Wal-Mart y Carrefour, no han tenido gran éxito o no han mostrado interés. Pero esto podría constituir un peligro, ya que en mercados en fuerte consolidación, las redes subregionales que están formando las empresas chilenas podrían transformarse en un objetivo de gran interés para operadores globales que deseen posicionarse rápida y sólidamente en América Latina. Un caso ilustrativo es la reciente adquisición por Wal-Mart de la cadena CARHC en América Central. 


\section{Bibliografía}

América economía (2006a): Las mayores empresas de América Latina, Santiago de Chile, 14 de julio-17 de agosto. (2006b): Santiago de Chile, 14 de abril a 4 de mayo.

A.T. Kearney (2004): Emerging Market Priorities for Global Retailers. The 2004 Global Retail Development Index. Disponible en http://www.atkearney.com.

(2005): Emerging Market Priorities for Global Retailers. The 2005 Global Retail Development Index. Disponible en http://www.atkearney.com.

(2006): Emerging Market Priorities for Global Retailers. The 2006 Global Retail Development Index. Disponible en http://www.atkearney.com.

(varios años): Emerging Market Priorities for Global Retailers. The 2006 Global Retail Development Index. Disponible en http://www.atkearney.com.

Bianchi, C. (2002): El proceso de internacionalización de Falabella, Caso $\mathrm{N}^{\circ} 44$, Santiago de Chile, Escuela de Negocios, Universidad Adolfo Ibáñez, septiembre.

Bianchi, C. y E. Ostalé (2004): Desafíos en la internacionalización de retailing: errores de empresas internacionales en Chile, Trend Management, vol. 6, edición especial, Santiago de Chile, Universidad Adolfo Ibáñez, mayo.

Business Latin America (2005): 14 de noviembre.

Calderón, Á. (2005): Chile: direct investment abroad and internationalization of conglomerates, documento preparado para la Reunión de expertos en el aumento de la capacidad de producción de las empresas de los países en desarrollo mediante la internacionalización (Ginebra, 5 al 7 de diciembre).

Calderón, Á. y S. Griffith-Jones (1995): Los flujos de capital extranjero en la economía chilena. Renovado acceso y nuevos usos, serie Desarrollo productivo, $N^{\circ} 24$, LC/G.1868, Santiago de Chile, Comisión Económica para América Latina y el Caribe (CEPAL), septiembre.

Capital (2006): Top 100, las mayores compañías por ventas, Santiago de Chile, 22 de abril.

Cencosud (2003): Memoria anual 2002 y estados financieros, Santiago de Chile.

(2004): Memoria anual 2003 y estados financieros, Santiago de Chile.

(2005): Memoria anual 2004 y estados financieros, Santiago de Chile.

(2006): Memoria anual 2005, Santiago de Chile.

CEPAL (Comisión Económica para América Latina y el Caribe) (2006): La inversión extranjera en América Latina y el Caribe, 2005,
LC/G.2309-P, Santiago de Chile, abril. Publicación de las Naciones Unidas, $\mathrm{N}^{\circ}$ de venta: S.06.II.G.44.

Chain Drug Review (2002): Nueva York, Racher Press, diciembre. Deloitte (2006): 2006 Global powers of retailing. Disponible en http://www.stores.org.

El Clarín (2005): Buenos Aires, 29 de abril.

El Mercurio (2002): Santiago de Chile, 5 de abril. (2005a): Santiago de Chile, 28 de julio. (2005b): Santiago de Chile, 19 de junio.

Estrategia (2004). Santiago de Chile, 2 de noviembre.

Falabella (2000): Memoria anual 1999, Santiago de Chile. (2001): Memoria anual 2000, Santiago de Chile. (2004a): Memoria anual 2003, Santiago de Chile. (2004b): Prospecto de emisión de bonos desmaterializados series $C$ y $D$, Santiago de Chile, noviembre.

(2005): Memoria anual 2004, Santiago de Chile. (2006): Memoria anual 2005, Santiago de Chile.

FASA (2002): Memoria anual 2001, Santiago de Chile, Farmacias Ahumada.

(2003): Memoria anual 2002, Santiago de Chile, Farmacias Ahumada.

(2005): Memoria anual 2004, Santiago de Chile, Farmacias Ahumada.

La Nación (2005): Santiago de Chile, 17 de diciembre.

La Segunda (2006): Santiago de Chile, 1 de septiembre.

La Tercera (2006a): Santiago de Chile, 20 de abril. (2006b): Santiago de Chile, 31 de agosto.

McKinsey Global Institute (2003): New Horizons: Multinational Company Investment in Developing Countries. Disponible en http:/www.mckinsey.com.

Qué Pasa (2006): № 1818, Santiago de Chile, 11 de febrero

Sodimac (2005): Memoria anual 2004, Santiago de Chile.

Stores (2006): 2006 Global powers of retailing, Deloitte, enero. Disponible en http://www.stores.or

The Wall Street Journal Americas (2005): Nueva York, 15 de diciembre.

UNCTAD (Conferencia de las Naciones Unidas sobre Comercio y Desarrollo) (1998): World Investment Report 1998: Trends and Determinants, Nueva York. Publicación de las Naciones Unidas, $\mathrm{N}^{\circ}$ de venta: E.98.II.D.5

(2005): World Investment Report 2005: Transnational Corporations and the Internationalization of $R \& D$, UNCTAD/ WIR/2005, Ginebra. Publicación de las Naciones Unidas, $N^{\circ}$ de venta: E.05.II.D.10. 